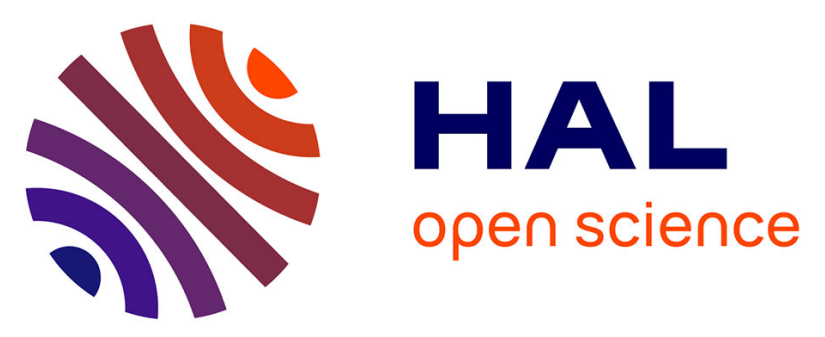

\title{
Sustained-Hepatic Arterial Infusion of oxaliplatin: pharmacokinetic advantages over Hepatic Arterial Infusion using a preclinical animal tumour model
}

Frederic Deschamps, Lambros Tselikas, Masako Tasaki, Shinji Motoyama, Thomas Isoardo, Michel Ducreux, Dragica Paunovic, Laurence Moine, Thierry de Baere

\section{To cite this version:}

Frederic Deschamps, Lambros Tselikas, Masako Tasaki, Shinji Motoyama, Thomas Isoardo, et al.. Sustained-Hepatic Arterial Infusion of oxaliplatin: pharmacokinetic advantages over Hepatic Arterial Infusion using a preclinical animal tumour model. Drug Delivery and Translational Research, In press, 11, pp.2144-2150. 10.1007/s13346-020-00881-7 . hal-03324619

\author{
HAL Id: hal-03324619 \\ https://hal.science/hal-03324619
}

Submitted on 23 Aug 2021

HAL is a multi-disciplinary open access archive for the deposit and dissemination of scientific research documents, whether they are published or not. The documents may come from teaching and research institutions in France or abroad, or from public or private research centers.
L'archive ouverte pluridisciplinaire HAL, est destinée au dépôt et à la diffusion de documents scientifiques de niveau recherche, publiés ou non, émanant des établissements d'enseignement et de recherche français ou étrangers, des laboratoires publics ou privés. 
Sustained-Hepatic Arterial Infusion of oxaliplatin: pharmacokinetic advantages over Hepatic Arterial Infusion using a preclinical animal tumour model

Frederic Deschamps ${ }^{1}$; Lambros Tselikas ${ }^{1,2}$; Masako Tasaki ${ }^{3}$; Shinji Motoyama ${ }^{3} ;$ T. Isoardo ${ }^{1,2}$; Michel Ducreux ${ }^{4,5}$; Dragica Paunovic ${ }^{6}$; Laurence Moine ${ }^{7}$; and Thierry de Baere $^{1,5}$.

${ }^{1}$ Interventional Radiology department, Gustave Roussy, Villejuif, France

${ }^{2}$ Laboratory of translational research in Immunology (LTRI), UMR 1015, Gustave Roussy, Villejuif, France.

${ }^{3}$ R\&D Center, Terumo Corporation, Kanagawa, Japan.

${ }^{4}$ Oncology department, Gustave Roussy, Villejuif, France.

${ }^{5}$ Université Paris-Saclay, Saint-Aubin, France

${ }^{6}$ Terumo Corporation, Interventional systems, Global Medical Affairs, Tokyo, Japan

${ }^{7}$ Institut Galien, CNRS. Paris-Sud university, Châtenay-Malabry, France. 


\section{Abstract}

Purpose: Hepatic Arterial Infusion (HAI) of oxaliplatin allows greater liver tumours drug exposure compared to systemic infusion. However, the therapeutic index of $\mathrm{HAl}$ oxaliplatin remains poor. Using Pickering emulsion technology, we developed a platform able to provide sustained releases of oxaliplatin. The goal of this study was to evaluate the pharmacokinetic advantages of sustained-HAI oxaliplatin over HAI using a preclinical animal tumour model.

Material and Methods: Injections of $0.6 \mathrm{mg}$ oxaliplatin in 20 minutes were selectively done in left hepatic arteries of 20 rabbits bearing a VX2 liver tumour in the middle left-lobe, using $\mathrm{HAI}(\mathrm{n}=10)$ or sustained-HAI $(n=10)$. In each group, half of the rabbits were sacrificed at $24 \mathrm{~h}$ and half at $72 \mathrm{~h}$. Mass-spectrometry was used to quantify drug pharmacokinetics in blood and oxaliplatin concentrations in tumour tissues, right- and middle left- liver lobes, spleen and lung.

Results: Compared to $\mathrm{HAI}$, sustained-HAl of oxaliplatin resulted in lower plasmatic peak (Cmax: $277 \pm 42$ vs. $420 \pm 121 \mathrm{ng} / \mathrm{mL}, \mathrm{p}<0.0001$ ) and higher concentration in the tumour at $24 \mathrm{~h}(2118 \pm 2107$ vs. $210 \pm 93 \mathrm{ng} / \mathrm{g}, \mathrm{p}=0.008)$. After $\mathrm{HAl}$, oxaliplatin concentration in tumours was significantly higher than in lung at $24 \mathrm{~h}$ $(p=0.03)$ but no other difference was found between oxaliplatin concentrations in tumours and in liver lobes, spleen or lung, neither at $24 \mathrm{~h}$ nor at $72 \mathrm{~h}$. On the opposite, sustained-HAl resulted in higher concentrations of oxaliplatin in tumour compared to oxaliplatin concentrations in the middle left lobe $(163 \pm 86 \mathrm{ng} / \mathrm{g}$ at $24 \mathrm{~h}, \mathrm{p}=0.01$ and 90 $\pm 15 \mathrm{ng} / \mathrm{g}$ at $72 \mathrm{~h}, \mathrm{p}=0.04)$, right lobe $(174 \pm 112 \mathrm{ng} / \mathrm{g}$ at $24 \mathrm{~h}, \mathrm{p}=0.01$ and $112 \pm 35 \mathrm{ng} / \mathrm{g}$, 
$\mathrm{p}=0.05$ at $72 \mathrm{~h})$, spleen $(142 \pm 21 \mathrm{ng} / \mathrm{g}$ at $24 \mathrm{~h}, \mathrm{p}=0.01$ and $98 \pm 12 \mathrm{ng} / \mathrm{g}$ at $72 \mathrm{~h}$, $p=0.04$ ) and lung ( $85 \pm 11 \mathrm{ng} / \mathrm{g}$ and $24 \mathrm{~h}, \mathrm{p}=0.01$ and $52 \pm 4 \mathrm{ng} / \mathrm{g}$ at $72 \mathrm{~h}, \mathrm{p}=0.03$ ).

Conclusion: sustained-HAI improves the therapeutic index of HAI oxaliplatin and offers a great potential for patients suffering from unresectable colorectal liver metastases or hepatocellular carcinoma. 


\section{Graphical abstract}

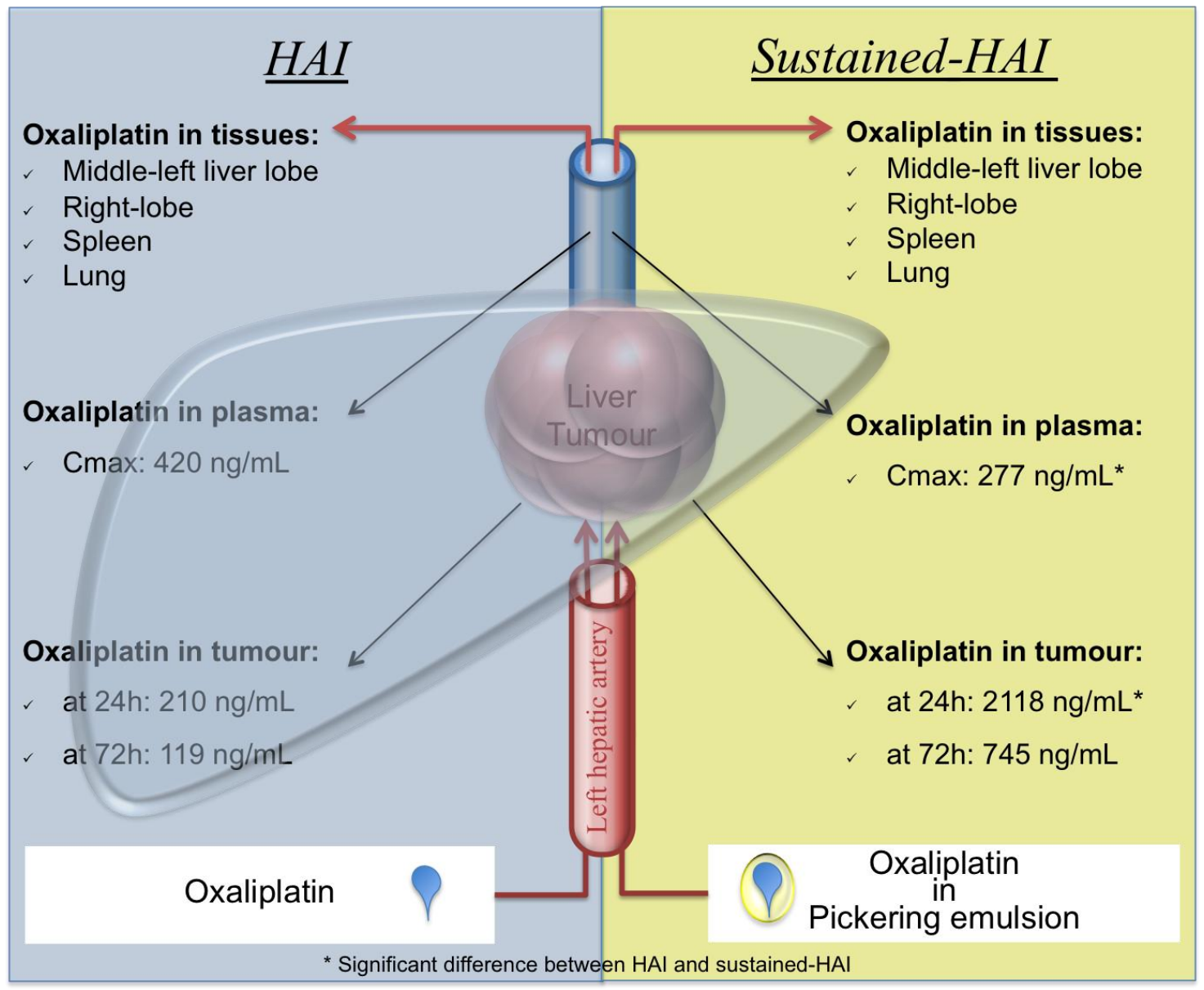




\section{Keywords}

Drug delivery system; platform; hepatic arterial infusion; oxaliplatin; liver tumors; nanoparticle; pickering; emulsion; Lipiodol; ethiodized oil 


\section{Introduction}

Treatment of unresectable liver tumours, both primary and metastases from other organs, remains a difficult challenge. Along with the development of new drugs, delivery of chemotherapy to the liver via Hepatic Arterial Infusion (HAI) has been developed to ensure greater local concentration of chemotherapy. HAI allows minimization of chemotherapy dilution, metabolism and elimination before reaching the liver tumours, increases local chemotherapy concentration, and decreases systemic exposure due to hepatic clearance ${ }_{[1][2][3]}$.

In colorectal metastatic disease, oxaliplatin is a pillar of many systemic regimens. Oxaliplatin is also of interest for the treatment of advanced hepatocellular carcinoma $(\mathrm{HCC})$ since a recent phase III trial evaluating treatment with systemic FOLFOX regimen for advanced HCC has provided better outcomes compared to doxorubicin [4]. Nowadays, oxaliplatin is used as HAl administration since combination with systemic fluorouracil and leucovorin, according to the LV5FU2 protocol, has been demonstrated feasible and effective in patients presenting with isolated hepatic metastases of colorectal cancer ${ }_{[5]}$. Interestingly, HAI oxaliplatin have demonstrated pharmacokinetic advantages, with lower systemic toxicity compared to systemic administration [6] [7].

However, oxaliplatin demonstrates a liver extraction ratio of 0.47 only ${ }_{[8]}$, meaning that approximately half of the oxaliplatin administrated via HAI reaches the systemic circulation resulting in systemic toxicities, including cumulative peripheral neuropathy, which often imposes to stop oxaliplatin before disease progression. In addition, $\mathrm{HAl}$ has never demonstrated a significant increase of oxaliplatin concentration in the tumour compared to systemic injection and as far as overall 
response rate and overall survival are concerned, benefit of HAI of oxaliplatin over systemic remains not clear even if randomized trials are on-going [9].

To further improve the therapeutic index of HAI of oxaliplatin, we developed the concept of sustained-HAl, which uses a platform that provides extended release of oxaliplatin. The goal of the platform is to act as a transient reservoir of oxaliplatin, allowing slow release of the chemotherapy into the liver arterial supply thus prolonging exposure of the tumour cells while minimizing systemic exposures.

The goal of this study was to evaluate the pharmacokinetic advantages of sustainedHAl over HAI for oxaliplatin using a preclinical animal tumour model.

\section{Materials/ methods}

The platform that we have developed for sustained-HAI of oxaliplatin is a "Pickering-emulsion" made of ethiodized oil (Lipiodol®) and polylactic-co-glycolic acid (PLGA) biodegradable nanoparticles [10] [11]. Emulsions of ethiodized oil are currently used for the local delivery of chemotherapy to unresectable hepatocellular carcinoma during liver trans-arterial chemo-embolization. Emulsion allows the release of hydrophilic anticancer drugs dissolved in the oily phase (water-in-oil emulsion) and radio-opacity of ethiodized oil ensures monitoring of the injection into the tumour feeder arteries under X-ray guidance. High stability of emulsion represents a major challenge. Pickering technology uses solid particles to stabilize the interfaces between an oily phase and an aqueous phase in emulsions [12] [13]. Compared with classical emulsions, Pickering-emulsions display outstanding stability. Biodegradable nanoparticles made of PLGA offer the advantage of being biocompatible and eliminated from the body, potentially reducing inflammatory reaction by their

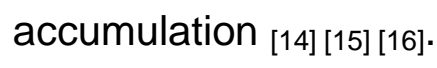




\section{Materials}

Poly(lactide-co-glycolide) (PLGA, 75:25) was provided by Evonik (Germany). Nanoparticles of PLGA were prepared by a nanoprecipitation process as previously described $_{[10]}$. Lipiodol® was purchased from Guerbet (France). Oxaliplatin (ELPLAT I.V. Infusion solution $50 \mathrm{mg}, 10 \mathrm{~mL} / \mathrm{vial}$ ) was provided by xxx.

\section{Emulsion formulation}

Pickering-emulsion of oxaliplatin was obtained by mixing 2 volumes of aqueous-phase (composed of oxaliplatin mixed with $15 \mathrm{mg} / \mathrm{mL}$ PLGA-NPs) with 3 volumes of oily-phase (composed of Lipiodol $($ )). PLGA-NPs used have an average diameter of $170 \pm 20 \mathrm{~nm}$, a Pdl of 0.08 and a negative zeta potential of $-4 \pm 1 \mathrm{mV}$. Repetitive pumping through a three-way stopcock with two $10 \mathrm{~mL}$ syringes and slow addition of the aqueous phase into the oily phase were performed in order to obtain stable water-in-oil emulsion ${ }_{[17]}$. Average droplet size after emulsification were $37 \pm$ $12 \mu \mathrm{m}$.

\section{Characterization}

The hydrodynamic diameter $\left(d_{H}\right)$ and polydispersity index (PDI) of the nanoparticles were measured by quasi elastic light scattering, using a Zetasizer Nano ZS instrument (Malvern, France). Suspensions were diluted in water to a concentration of $1 \mathrm{mg} / \mathrm{mL}$. Measurements were performed at $20^{\circ} \mathrm{C}$, at an angle of $173^{\circ}$ to avoid multiple scattering. Zeta potential measurements were carried out with the same instrument, at $25^{\circ} \mathrm{C}$, in $1 \mathrm{mM} \mathrm{NaCl}$. Measurements were performed in triplicate. 
The droplet size of emulsion was determined by flow imaging microscopy on a Flowcell FC200S+HR (Occhio, Belgium). Thanks to image analysis, the Flowcell apparatus measures the size and the morphology of droplets. The emulsion was first diluted 20 times in oil. Then $0.5 \mathrm{~mL}$ of the diluted emulsion was passed through a $300 \mu \mathrm{m}$ spacer to get a size range between 5 and $300 \mu \mathrm{m}$. From images, the size expressed as the volume median diameter $\left(d_{50}\right)$ of five measurements were determined.

\section{$\underline{\text { In vitro release test }}$}

Oxaliplatin release: $0.8 \mathrm{~mL}$ of a freshly prepared emulsion (equivalent to an amount of $1.6 \mathrm{mg}$ of oxaliplatin) was placed into GeBAflex dialyse tube with pores of $14 \mathrm{kDa}$ (GeBa, Israel). The tubes were immersed into $40 \mathrm{~mL}$ of $25 \mathrm{mM}$ acetate buffer $(\mathrm{pH}=6.8)$. Then, the whole release system was placed in an orbital shaker at $37^{\circ} \mathrm{C}$ for the entire duration of the experiment. Before each aliquot withdrawing, the tubes were vortexed and the medium was entirely collected and replaced by fresh acetate buffer solution. The released amounts of platin in the buffer solution were assessed by means of flameless atomic absorption spectrophotometry at $265.9 \mathrm{~nm}$ with a Perkin Elmer PINAACLE 900Z. Platinum levels were quantified after preparing calibration curves with atomic platinum.

\section{$\underline{\text { In vivo test }}$}

This study was performed in accordance with local institutional Animal Care and Use Committee guidelines. Twenty New Zealand White rabbits (21 weeks old, $3.46 \pm 0.13 \mathrm{~kg}$ ), bearing a VX2 tumour implanted in the middle left liver lobe, received selective arterial infusion of oxaliplatin (ELPLAT I.V. Infusion solution $50 \mathrm{mg}, 10$ 
$\mathrm{mL} / \mathrm{vial}$ ) in the left hepatic artery. Intra-arterial delivery of oxaliplatin was performed under general anesthesia and fluoroscopic guidance (Infinix-Celeve-I,Toshiba Medical Systems). First, the femoral artery was surgically exposed and canulated with a $4 \mathrm{~F}$ vascular sheath using a Seldinger approach. Then, a microcatheter (Progreat Lambda 1.7F, Terumo, Tokyo, Japan) was inserted into the hepatic artery (Figure 1) and used for the infusion of oxaliplatin into the left hepatic artery under the following conditions: infusion volume, $0.3 \mathrm{~mL}$; infusion time, $20 \mathrm{~min}$. Oxaliplatin was administrated either diluted with $5 \%$ glucose solution, in a 2/3 ratio (HAl group, $n=10$ rabbits) or "loaded" into Pickering-emulsion in a 2/3 ratio (sustained-HAl group, $n=10$ rabbits). For each group the total amount of oxaliplatin delivered in the left liver lobe was $0.6 \mathrm{mg}$.

After completion of arterial delivery of oxaliplatin in the left liver lobes, plasma samples $(1 \mathrm{~mL})$ were taken from the femoral vein at baseline and at 5, 10, 20, 30, 60 minutes and 24 hours in order to compare the pharmacokinetic (PK) profiles of the 2 groups. For both groups, 5 rabbits were sacrificed 24 hours after the procedure and 5 rabbits were sacrificed 72 hours after the procedure. After sacrificed, fresh tissue samples were taken from liver tumour, from non-tumoural liver (right lobe and middle lobe) and from other organs (spleen and lungs) for oxaliplatin quantification.

\section{Oxaliplatin quantification}

Aliquot of each plasma sample $(0.1 \mathrm{~mL})$ and aliquot of each tissue sample homogenate $(0.1 \mathrm{ML})$ were mixed with nitric acid $(1 \mathrm{~mL})$ and hydrochloric acid $(0.2$ $\mathrm{mL}$ ). The samples were heated using a microwave digestion system (ETHOS 1, Milestone) at $180^{\circ} \mathrm{C}$ for $20 \mathrm{~min}$. After cooling, the solutions were transferred to centrifuge tubes and brought to a fixed volume using ultrapure water. The resulting 
solutions were submitted for ICP-MS analysis (ELAN DRC, PerkinElmer). Platinum (195Pt) was analyzed using calibration standard solutions.

The calibration standard solutions $(0,1,2,5$, and $10 \mathrm{ng} / \mathrm{mL})$ were formulated by diluting $1000 \mathrm{mg} / \mathrm{L}$ platinum standard solution (Kanto Chemical) with the blank solution (10\% nitric acid and $2 \%$ hydrochloric acid). Finally, the concentration data for 195Pt analyzed via ICP-MS were converted into oxaliplatin concentration data.

\section{Data analysis and statistical analysis}

PK parameters were calculated using Phoenix WinNonlin version 6.3. build 0.395 (Certara). A data sampling period from 0 to 72 hours using the noncompartment model was used for PK parameter analysis which included the maximum plasma concentration (Cmax), the area under the plasma concentration curve from 0 to $24 \mathrm{~h}(\mathrm{AUC} 0-24 \mathrm{~h})$, the elimination half-life $\left(\mathrm{t}_{1 / 2}\right)$, the volume of distribution $(\mathrm{Vd})$ and the clearance $(\mathrm{CL})$ of oxaliplatin.

Data were presented as the mean value \pm standard deviation (SD). The mean and SD were calculated for administration time, body weights, plasma concentrations, PK parameters, and tissue concentrations in each group using Microsoft Excel 2016 MSO (16.0.4549.1000). Statistical analysis for these data was conducted using Prism 8 (GraphPad Software). Mann-Whitney U test was used to compare data between HAl group and sustained-HAl group. Dunnett's multiple comparisons test was used to compare oxaliplatin in tumour with other tissues in both groups. $\mathrm{P}<0.05$ was considered statistically significant.

\section{Results}




\section{In vitro release test}

The oxaliplatin release profiles of Pickering-emulsion and oxaliplatin solution are shown in Figure 2. Oxaliplatin was rapidly released with the solution compared to the Pickering-emulsion ( $84 \pm 21 \%$ vs $21 \pm 4 \%$ respectively in $24 \mathrm{~h}$ ).

\section{$\underline{\text { In vivo test }}$}

The tumour dimensions were similar between rabbits in sustained-HAl group and in HAl group: mean tumour volume of $0.42+/-0.2$ vs. $0.47+/-0.17 \mathrm{~cm} 3$ and mean long axis diameter of $1.02+/-0.15$ vs. $1.25+/-0.16 \mathrm{~cm}$.

The oxaliplatin concentration in plasma is shown in Figure 3 and PK parameters in Table 1. The oxaliplatin concentrations in plasma were significantly lower in the sustained-HAI group than in the HAI-group 0, 5 10, 15 and 20 minutes after completion of arterial delivery. The Cmax of oxaliplatin was significantly lower in in the sustained-HAI group compared to the HAI group (277 \pm 42 vs. $420 \pm 121 \mathrm{ng} / \mathrm{mL}$, $\mathrm{p}<0.0001)$. The other PK parameters were not significantly different between the sustained-HAI group and the HAl group (AUC0-24h, Vd, CL).

Oxaliplatin concentrations in tissues are shown in Table 2. The concentration of oxaliplatin in the tumour was statistically higher in the sustained-HAl group than in the $\mathrm{HAl}$ at $24 \mathrm{~h}(2118 \pm 2107$ vs. $210 \pm 93 \mathrm{ng} / \mathrm{g}, \mathrm{p}=0.008)$, no difference was observed at $72 \mathrm{~h}(745 \pm 841$ vs. $119 \pm 54 \mathrm{ng} / \mathrm{g})$. No other difference were observed between the 2 groups in other tissues except for lung where oxaliplatin concentration was significantly lower in sustained-HAl compared to HAl group at $72 \mathrm{~h}(52 \pm 4 \mathrm{ng} / \mathrm{g}$ vs. $73 \pm 19 \mathrm{ng} / \mathrm{g}, \mathrm{p}=0.02)$.

In the sustained-HAl group, oxaliplatin concentrations in the tumour at $24 \mathrm{~h}$ was significantly higher than in the middle left lobe (163 $\pm 86 \mathrm{ng} / \mathrm{g}, \mathrm{p}=0.01)$, right lobe 
(174 $\pm 112 \mathrm{ng} / \mathrm{g}, \mathrm{p}=0.01)$, spleen $(142 \pm 21 \mathrm{ng} / \mathrm{g}, \mathrm{p}=0.01)$ and lung $(85 \pm 11 \mathrm{ng} / \mathrm{g}$ $\mathrm{p}=0.01$ ). At $72 \mathrm{~h}$, the concentration of oxaliplatin in the tumour was significantly higher than in the middle left lobe $(90 \pm 15 \mathrm{ng} / \mathrm{g}, \mathrm{p}=0.04)$, spleen $(98 \pm 12 \mathrm{ng} / \mathrm{g}, \mathrm{p}=0.04)$ and lung (52 $\pm 4 \mathrm{ng} / \mathrm{g}, \mathrm{p}=0.03)$.

In the HAI group, oxaliplatin concentrations in the tumour at $24 \mathrm{~h}$ and at $72 \mathrm{~h}$ were not statistically higher than in other tissues except in lung at $24 \mathrm{~h}(210 \pm 93 \mathrm{ng} / \mathrm{g}$ vs. $95 \pm 5 \mathrm{ng} / \mathrm{g} \mathrm{p}=0.03)$.

\section{Discussion}

$\mathrm{HAI}$ of oxaliplatin is a valid option for the treatment of unresectable colorectal liver metastases with $90 \%$ overall response rate (ORR) in first-line treatment when combined with systemic 5-FU + cetuximab allowing surgical resection of initially unresectable metastases in $48 \%$ of the patients [18]. Moreover, the ORR was $54 \%$ in patients who are not any more responders to systemic oxaliplatin, demonstrating that high local concentration of oxaliplatin results in higher response rate ${ }_{[19]}$. Despite high ORR, HAI of oxaliplatin has never demonstrated improvement in OS compared to systemic treatment, except for patients who benefit of surgical resection after high response rate ${ }_{[20]}$. In addition, $\mathrm{HAl}$ oxaliplatin has a first-pass extraction rate that is $47 \%$, and a plasma half- life of $15-19$ hours [21], resulting in oxaliplatin-related systemic toxicity even if oxaliplatin is infused in the hepatic arteries with reported grade 3-4 neutropenia (43\%) and grade 2-3 neuropathy (43\%) [22].

For patients with advanced HCC, several studies have explored $\mathrm{HAl}$ of oxaliplatin and demonstrated that it is effective, well tolerated [23] [24] [25] and improved overall survival compared to sorafenib (respectively 14.5 vs. 7.0 months; $p<0.001$ ) [26]. Optimizing HAI of oxaliplatin can help to further improve outcomes. 
Our experimental study demonstrates that the use of pickering-emulsion by allowing a sustained release of oxaliplatin is responsible for higher therapeutic index when compared to HAI. The pickering-emulsion herein reported is an emulsion stabilized by PLGA NPs. The addition of these biodegradable and biocompatible NPs into the oxaliplatin improves stability of the emulsion by modification of the emulsification process with ethiodized-oil [10]. The sustained release of oxaliplatin from Pickering-emulsion have been demonstrated in-vitro and in preliminary animal study $[11]$.

In this study, we demonstrate that sustained-HAl of oxaliplatin in the left liver artery improves tumour drug exposure while concentrations of oxaliplatin in the healthy liver (right and left lobe) remains similar to HAI. Tumour drug exposure is 10times higher at 24h using sustained-HAI versus HAl. In addition, sustained-HAI allows a significant increase of the oxaliplatin concentration in the tumour compared to liver, spleen and lung, at least for $72 \mathrm{~h}$ after the arterial infusion. Such pharmacokinetic benefit offers great opportunities to further increase the overall response rate to oxaliplatin in liver tumours and decreases systemic toxicities.

\section{Conclusion}

We demonstrate that sustained-HAI of oxaliplatin results in lower plasmatic peak and greater tumour drug exposure at $24 \mathrm{~h}$ compared to HAl. In addition, sustained-HAl allows a significant increase of the oxaliplatin concentration in the tumour compared to liver, spleen and lung, at least for $72 \mathrm{~h}$ after the arterial infusion. Major improvement in the therapeutic index of sustained-HAI with oxaliplatin may offer a great potential for patients suffering from unresectable colorectal liver metastases or hepatocarcinoma. 



\section{Statements}

All institutional and national guidelines for the care and use of laboratory animals were followed

Terumo Corporation, Kanagawa, Japan, has founded this work. Dragica Paunovic, Masako Tasaki and Shinji Motoyama are employees of Terumo Corporation and declare conflicts of interest with Terumo corporation. 


\section{References}

1. Doussot, A.; Kemeny, N.E.; D’Angelica, M.I. Hepatic arterial infusional chemotherapy in the management of colorectal cancer liver metastases. Hepatol. Oncol. 2015, 2, 275-290] [Chapelle, N.; Matysiak-Budnik, T.; Douane, F.; Metairie, S.; Rougier, P.; Touchefeu, Y. Hepatic arterial infusion in the management of colorectal cancer liver metastasis: Current and future perspectives. Dig. Liver Dis. $2018,50,220-225$

2. Karanicolas, P.J.; Metrakos, P.; Chan, K.; Asmis, T.; Chen, E.; Kingham, T.P.; Kemeny, N.; Porter, G.; Fields, R.C.; Pingpank, J.; et al. Hepatic arterial infusion pump chemotherapy in the management of colorectal liver metastases: Expert consensus statement. Curr. Oncol. 2014, 21, e129

3. Ensminger, W.D.; Gyves, J.W. Clinical pharmacology of hepatic arterial chemotherapy. Semin. Oncol. 1983,10, 176-182

4. Qin S, Bai Y, Lim HY, Thongprasert S, Chao Y, Fan J, et al. Randomized, multicenter, open-label study of oxaliplatin plus fluorouracil/leucovorin versus doxorubicin as palliative chemotherapy in patients with advanced hepatocellular carcinoma from Asia. J Clin Oncol 2013;31:3501-8.

5. Ducreux M, Ychou M, Laplanche A, Gamelin E, Lasser P, Husseini F, Quenet F, Viret F, Jacob JH, Boige V, Elias D, Delperro JR, Luboinski M; gastrointestinal group of the Federation Nationale des Centres de Lutte Contre le Cancer. Hepatic arterial oxaliplatin infusion plus intravenous chemotherapy in colorectal cancer with inoperable hepatic metastases: a trial of the gastrointestinal group of the Federation Nationale des Centres de Lutte Contre le Cancer. J Clin Oncol. 2005 Aug $1 ; 23(22): 4881-7$. 
6. Kern, W.; Beckert, B.; Lang, N.; Stemmler, J.; Beykirch, M.; Stein, J.; Goecke, E.; Waggershauser, T.; Braess, J.; Schalhorn, A.; et al. Phase I and pharmacokinetic study of hepatic arterial infusion with oxaliplatin in combination with folinic acid and 5fluorouracil in patients with hepatic metastases from colorectal cancer. Ann. Oncol. 2001, 12, 599-603.

7. Dzodic, R.; Gomez-Abuin, G.; Rougier, P.; Bonnay, M.; Ardouin, P.; Gouyette, A.; Rixe, O.; Ducreux, M.; Munck, J.-N. Pharmacokinetic advantage of hepatic oxaliplatin administration: Comparative results with cisplatin using a rabbit VX2 tumor model. Anticancer Drugs 2004, 15, 647-650.

8. Guthoff, I.; Lotspeich, E.; Fester, C.; Wallin, I.; Schatz, M.; Ehrsson, H.; Kornmann, M. Hepatic artery infusion using oxaliplatin in combination with 5fluorouracil, folinic acid and mitomycin C: Oxaliplatin pharmacokinetics and feasibility. Anticancer Res. 2003, 23, 5203-5208.

9. Ranieri G, Laforgia M, Nardulli P, Ferraiuolo S, Molinari P, Marech I, Gadaleta CD. Oxaliplatin-Based Intra-arterial Chemotherapy in Colo-Rectal Cancer Liver Metastases: A Review from Pharmacology to Clinical Application. Cancers (Basel). 2019 Jan 24;11(2).

10. Deschamps F, Isoardo T, Denis S, Tsapis N, Tselikas L, Nicolas V, Paci A, Fattal E, de Baere T, Huang N, Moine L. Biodegradable Pickering emulsions of Lipiodol for liver trans-arterial chemo-embolization. Acta Biomater. 2019 Mar 15;87:177-186.

11. Deschamps F, Harris KR, Moine L, Li W, Tselikas L, Isoardo T, Lewandowski RJ, Paci A, Huang N, de Baere T, Salem R, Larson AC. Pickering-Emulsion for Liver Trans-Arterial Chemo-Embolization with Oxaliplatin. Cardiovasc Intervent Radiol. 2018 May;41(5):781-788. 
12. W. Ramsden, Separation of Solids in the Surface-Layers of Solutions and "Suspensions" (Observations on Surface-Membranes, Bubbles, Emulsions, and Mechanical Coagulation). -- Preliminary Account, Proc. R. Soc. London. 72 (1903) 156-164. doi:10.1098/rspl.1903.0034.

13. S.U. Pickering, CXCVI.-Emulsions, J. Chem. Soc., Trans. 91 (1907) 20012021. doi:10.1039/CT9079102001.

14. L.A. Guzman, V. Labhasetwar, C. Song, Y. Jang, A.M. Lincoff, R. Levy, E.J. Topol, Local intraluminal infusion of biodegradable polymeric nanoparticles. A novel approach for prolonged drug delivery after balloon angioplasty., Circulation. 94 (1996) 1441-8. http://www.ncbi.nlm.nih.gov/pubmed/8823004 (accessed August 22, 2018).

15. N. Grabowski, H. Hillaireau, J. Vergnaud, N. Tsapis, M. Pallardy, S. KerdineRömer, E. Fattal, Surface coating mediates the toxicity of polymeric nanoparticles towards human-like macrophages., Int. J. Pharm. 482 (2015) 75-83. doi:10.1016/j.ijpharm.2014.11.042.

16. N. Grabowski, H. Hillaireau, J. Vergnaud-Gauduchon, V. Nicolas, N. Tsapis, S. Kerdine-Römer, E. Fattal, Surface-Modified Biodegradable Nanoparticles' Impact on Cytotoxicity and Inflammation Response on a Co-Culture of Lung Epithelial Cells and Human-Like Macrophages., J. Biomed. Nanotechnol. 12 (2016) 135-46.

17. Deschamps F, Moine L, Isoardo T, Tselikas L, Paci A, Mir LM, Huang N, Fattal E, de Baère T. Parameters for Stable Water-in-Oil Lipiodol Emulsion for Liver TransArterial Chemo-Embolization. Cardiovasc Intervent Radiol. 2017 Dec;40(12):19271932.

18. D. Malka, E. Paris, C. Caramella, E. Boucher, R. Guimbaud, A. Celebic, T. De Baere, D. Elias, J. Pignon, M. Ducreux. Hepatic arterial infusion (HAl) of oxaliplatin 
plus intravenous (iv) fluorouracil (FU), leucovorin (LV), and cetuximab for first-line treatment of unresectable colorectal liver metastases (CRLM) (CHOICE): A multicenter phase II study. J Clin Oncol 28:15s, 2010 (suppl; abstr 3558).

19. Boige V, Malka D, Elias D, Castaing M, De Baere T, Goere D, Dromain C, Pocard M, Ducreux M. Hepatic arterial infusion of oxaliplatin and intravenous LV5FU2 in unresectable liver metastases from colorectal cancer after systemic chemotherapy failure. Ann Surg Oncol. 2008 Jan;15(1):219-26.

20. Goere D, Deshaies I, de Baere T, Boige V, Malka D, Dumont F, Dromain C, Ducreux M, Elias D. Prolonged survival of initially unresectable hepatic colorectal cancer patients treated with hepatic arterial infusion of oxaliplatin followed by radical surgery of metastases. Ann Surg. 2010 Apr;251(4):686-91.

21. Guthoff, I.; Lotspeich, E.; Fester, C.; Wallin, I.; Schatz, M.; Ehrsson, H.; Kornmann, M. Hepatic artery infusion using oxaliplatin in combination with 5fluorouracil, folinic acid and mitomycin C: Oxaliplatin pharmacokinetics and feasibility. Anticancer Res. 2003, 23, 5203-5208.

22. Boige V, Malka D, Elias D, Castaing M, De Baere T, Goere D, Dromain C, Pocard M, Ducreux M.Hepatic arterial infusion of oxaliplatin and intravenous LV5FU2 in unresectable liver metastases from colorectal cancer after systemic chemotherapy failure. Ann Surg Oncol. 2008 Jan;15(1):219-26.

23. Lyu N, Lin Y, Kong Y, Zhang Z, Liu L, Zheng L, et al. FOXAl: a phase II trial evaluating the efficacy and safety of hepatic arterial infusion of oxaliplatin plus fluorouracil/leucovorin for advanced hepatocellular carcinoma. Gut Published Online First: 07 June 2017. doi: 10.1136/gutjnl-2017-314138. 
24. Rathore R, Safran H, Soares G, Dubel G, McNulty B, Ahn S, et al. Phase I study of hepatic arterial infusion of oxaliplatin in advanced hepatocellular cancer: a brown university oncology group study. Am J Clin Oncol 2010;33:43-6.

25. Lyu N, Kong Y, Pan T, Mu L, Li S, Liu Y, Deng H, Li J, Shi M, Xu L, Guo R, Chen M, Wu P, Zhao M. Hepatic Arterial Infusion of Oxaliplatin, Fluorouracil, and Leucovorin in Hepatocellular Cancer with Extrahepatic Spread. J Vasc Interv Radiol. 2019 Mar;30(3):349-357.e2. doi: 10.1016/j.jvir.2018.09.004.

26. Ning Lyu, Yanan Kong, Luwen Mu, Youen Lin, Jibin Li, Yaru Liu, Zhenfeng Zhang, Lie Zheng, Haijing Deng, Shaolong Li, Qiankun Xie, Rongping Guo, Ming Shi, Li Xu, Xiuyu Cai, Peihong Wu, Ming Zhao. Hepatic Arterial Infusion of Oxaliplatin plus Fluorouraci//Leucovorin versus Sorafenib for Advanced Hepatocellular Carcinoma, J Hepatol. 2018 Jul;69(1):60-69. doi: 10.1016/j.jhep.2018.02.008. 


\begin{tabular}{|c|c|c|c|}
\hline Time & HAI & sustained-HAI & $p$ value \\
\hline $0 \mathrm{~min}$ & $377 \pm 110$ & $244 \pm 58$ & 0.002 \\
\hline $5 \mathrm{~min}$ & $379 \pm 94$ & $247 \pm 38$ & $<0.0001$ \\
\hline $10 \mathrm{~min}$ & $308 \pm 91$ & $214 \pm 35$ & 0.001 \\
\hline $15 \min$ & $248 \pm 84$ & $184 \pm 26$ & 0.005 \\
\hline $20 \mathrm{~min}$ & $216 \pm 74$ & $163 \pm 20$ & 0.009 \\
\hline $30 \mathrm{~min}$ & $172 \pm 61$ & $142 \pm 21$ & NS \\
\hline $60 \mathrm{~min}$ & $146 \pm 48$ & $131 \pm 22$ & NS \\
\hline $24 \mathrm{~h}$ & $52 \pm 13$ & $60 \pm 11$ & NS \\
\hline $\mathrm{C}_{\max }(\mathrm{ng} / \mathrm{mL})$ & $399 \pm 90$ & $268 \pm 46$ & $<0.0001$ \\
\hline$t_{1 / 2}(\min )$ & $900 \pm 133$ & $1231 \pm 321$ & NS \\
\hline $\mathrm{AUC}_{0-24 \mathrm{~h}}(\mathrm{ng} \cdot \mathrm{min} / \mathrm{mL})$ & $149901 \pm 45616$ & $141105 \pm 18628$ & NS \\
\hline $\mathrm{Vd}(\mathrm{mL})$ & $3786 \pm 1016$ & $4258 \pm 653$ & NS \\
\hline $\mathrm{CL}(\mathrm{mL} / \mathrm{min})$ & $2.91 \pm 0.67$ & $2.0 \pm 0.54$ & NS \\
\hline
\end{tabular}

Mean value \pm SD

NS : not significant, $\mathrm{P}>0.05$

HAI: Hepatic Arterial Infusion 


\begin{tabular}{|c|c|c|c|}
\hline Time & HAI & sustained-HAI & p value \\
\hline \multicolumn{4}{|l|}{ At $24 h$} \\
\hline Tumour & $210 \pm 93$ & $2118 \pm 2107$ & 0.008 \\
\hline Liver (middle-left lobe) & $143 \pm 77$ & $163 \pm 86$ & NS \\
\hline Liver (Right-lobe) & $160 \pm 94$ & $174 \pm 112$ & NS \\
\hline Spleen & $118 \pm 22$ & $142 \pm 21$ & NS \\
\hline Lung & $95 \pm 5$ & $85 \pm 11$ & NS \\
\hline \multicolumn{4}{|l|}{ At $72 h$} \\
\hline Tumour & $119 \pm 54$ & $745 \pm 841$ & NS \\
\hline Liver (middle-left lobe) & $201 \pm 174$ & $90 \pm 15$ & NS \\
\hline Liver (Right-lobe) & $139 \pm 55$ & $112 \pm 35$ & NS \\
\hline Spleen & $125 \pm 55$ & $98 \pm 12$ & NS \\
\hline Lung & $73 \pm 19$ & $52 \pm 4$ & 0.02 \\
\hline
\end{tabular}

Mean value \pm SD

NS : not significant, $\mathrm{P}>0.05$

HAI: Hepatic Arterial Infusion 
Figure 1: Intra-arterial deliveru of oxaliplatin in the left liver lobes

A/ Aortography

B/ Selective catheterization of the left hepatic branch (White arrow)

C/ Left liver lobes infused with oxaliplatin (area included in white dots points)

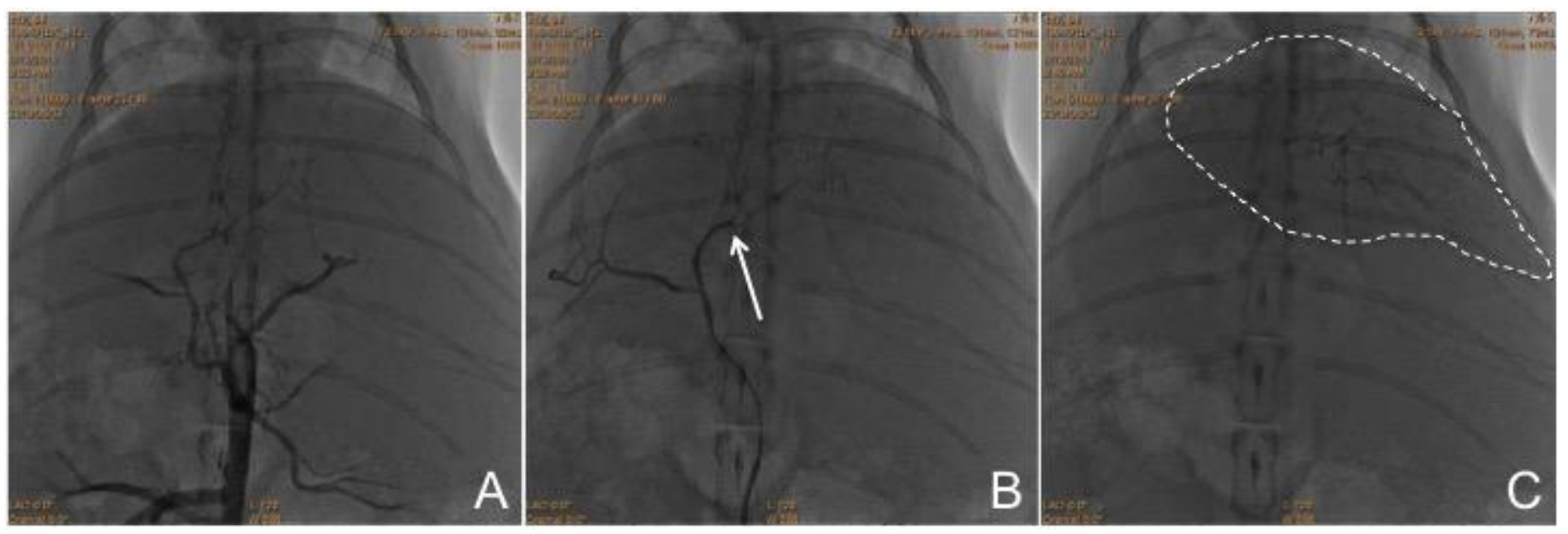


Figure 2: Oxaliplatin release profiles from the oxaliplatin solution alone and the $2 / 3$ oxaliplatin Pickering-emulsion. each point indicates mean+/- standard deviation $(n=5)$

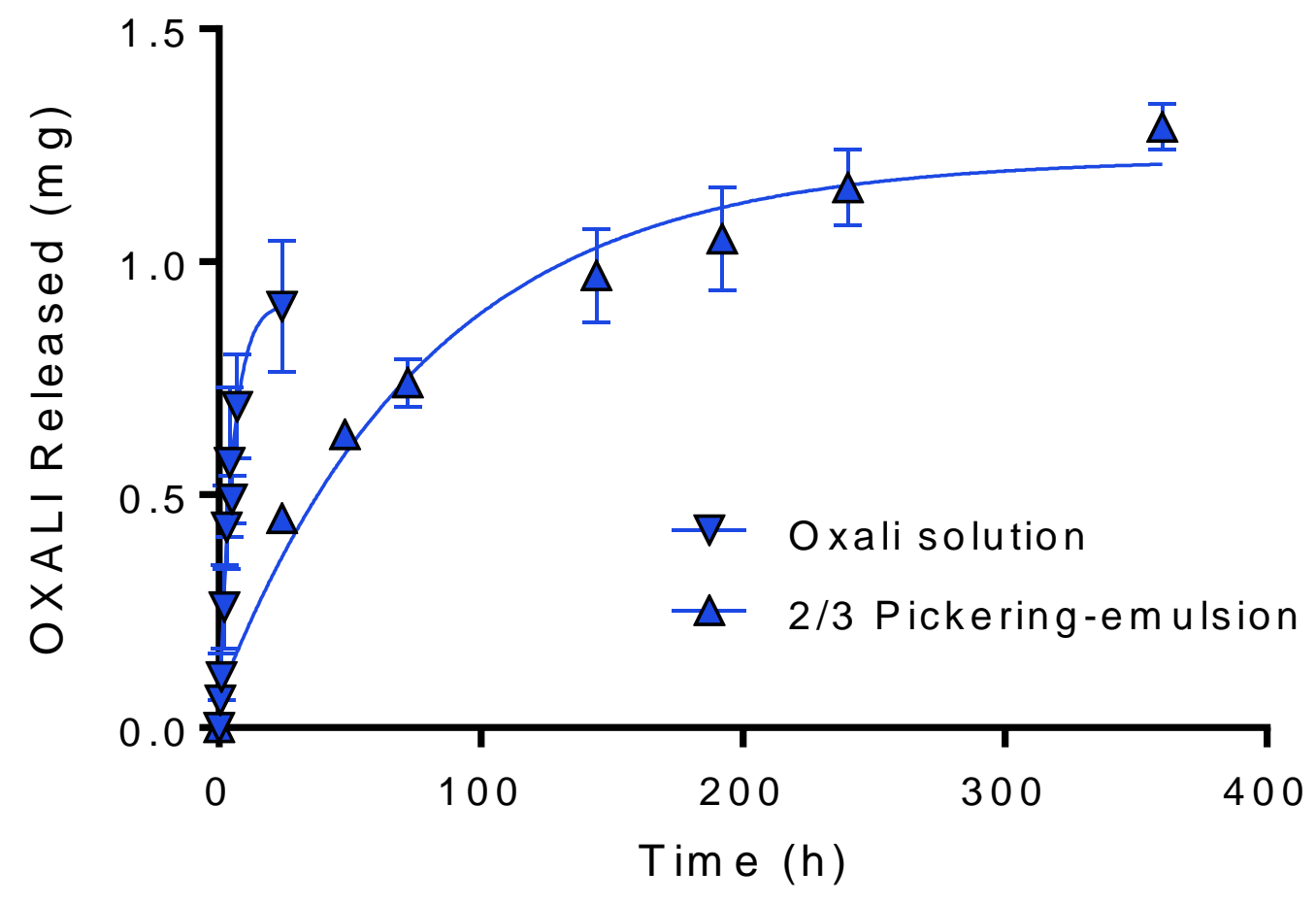


Figure 3: Concentration of oxaliplatin in plasma after completion of arterial delivery in the left hepatic branch.

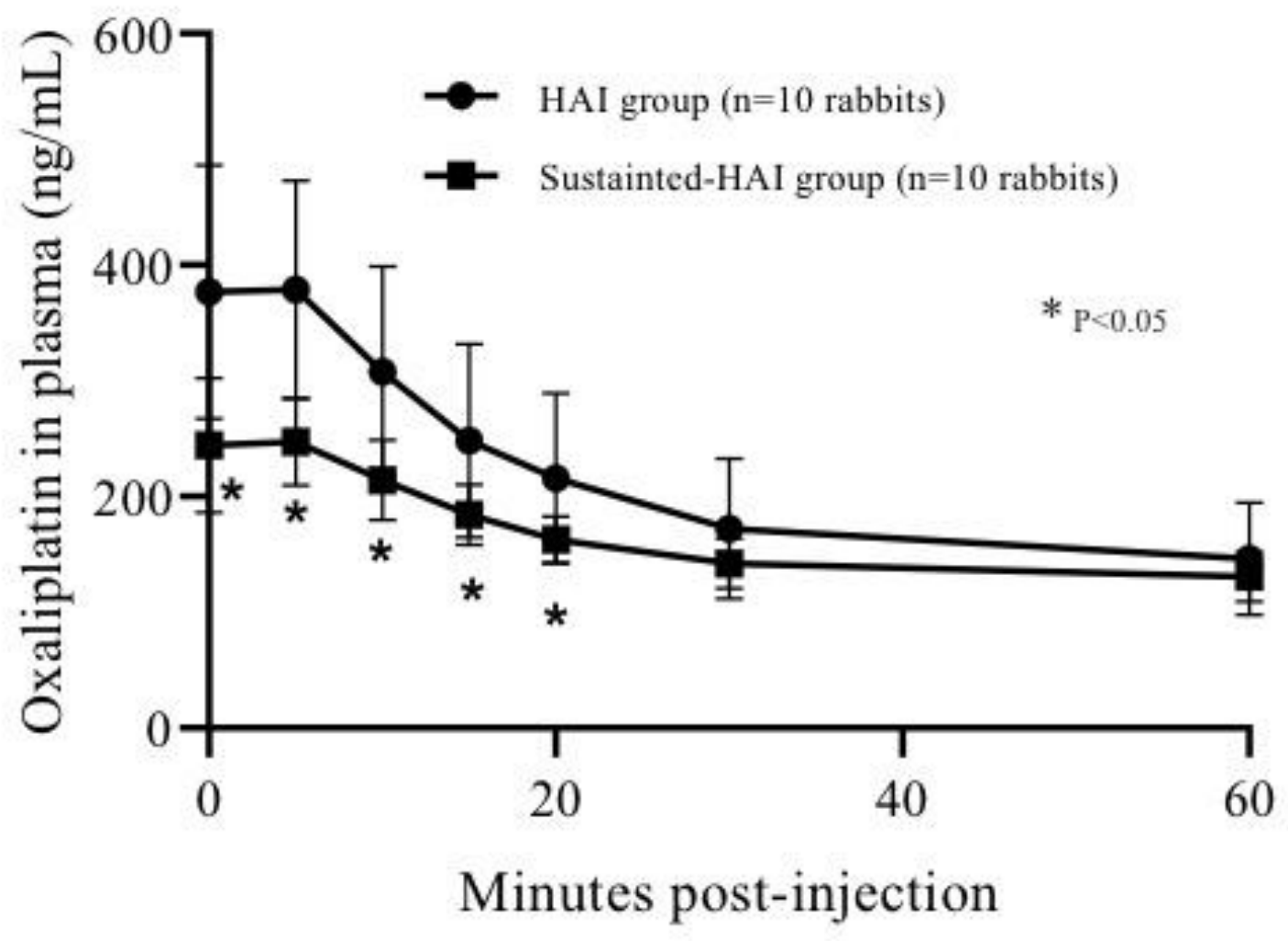

